\title{
ACCEPTANCE ANd READiness Of MOBILE LEARNING INTEGRATION AMONG TEACHERS OF Dyslexic STUdents: A Preliminary STUdy
}

\author{
Nor Zuhaidah Mohamed Zain ${ }^{1}$ and Murni Mahmud ${ }^{2}$ \\ ${ }^{1}$ Department of Computing, FSKIK, UPSI \\ ${ }^{2}$ Kuliyyah of Information and Communication Technology, IIUM
}

\begin{abstract}
Mobile technology enables the creation of mobile applications to assist learning. However, integrating the most appropriate mobile applications as an assistive technology for dyslexic students is challenging for teachers if they are unprepared with sufficient knowledge. This preliminary study aimed to understand the acceptance and readiness of mobile learning integration among teachers of dyslexic students. The study was a qualitative study, which involved one selected mobile application to be evaluated by four selected teachers. Teachers had been interviewed. Interestingly, the teachers showed positive attitude in acceptance and readiness of using mobile application in class, with condition it suits dyslexic students learning needs. They believe using appropriate mobile application can support learning. Following this study, more studies will be conducted to evaluate the effectiveness of abundant implementation towards mobile learning by teachers of dyslexic learning.
\end{abstract}

\section{KEYWORDS}

Mobile Learning, Mobile Application, Learning Disabilities, Assistive Technology, Dyslexic Students

\section{INTRODUCTION}

The development of information and communication technologies (ICT) in education include the adoption of general components of ICT in learning process. A significant amount of research has proven that ICT can have positive effects on learning [1]. Mobile technology and mobile learning (m-learning) are two related terms that sometimes can bring the same meaning in its context. The mechanism of m-learning includes the use of mobile devices like mobile phones, iPad, Personal Digital Assistants (PDAs) and Tablet PC. According to Aliff Nawi et al. [2], m-learning had created a method of learning that showed differences compared to conventional methods commonly used in teaching and learning. Integrating m-learning in classroom environment would be an effortless action if teachers or educators do not grab the opportunity to use mobile technology in classroom setting.

Being a teacher in the fast-moving technology use is definitely not an easy task. Problems as well as challenges in teaching, especially when the students are student with special education needs (SEN), are totally unpredictable and challenging. Research in both educational theory and cognitive psychology claims that SEN students are not the same and have different learning styles that refer to a range of different theories about individuals' learning [3]. With the introduction of mobile technology in learning environment, teachers then need to upgrade their social interaction towards SEN students' learning and expand related knowledge to cater the respective students' needs. 
The International Journal of Multimedia \& Its Applications (IJMA) Vol.10, No.6, December 2018

Simultaneously, parents or teachers look for effective mobile applications (MA) that meet the needs of their children and students respectively. This have often been a challenge for them due to the large number of education apps that are available in the market. It is challenging to find appropriate apps among many that are available, and this has caused a slight problem to the parties involved. In reality, these parents and teachers who work with the students seek apps that are valid for academic improvement [4]. "ABC Reading Magic Series", "Root Words" and "Action Words" are some interesting mobile application that are listed for dyslexic students. These MA have their own features and focus of development.

Not surprisingly, however, they often express challenges in finding effective apps. As short-listed by The Regents of the University of Michigan [5], there are an extensive list of mobile apps that may be helpful to individuals with dyslexia, parents of dyslexic students or the professionals who work with dyslexics (namely teachers and reading specialists). Integrating an appropriate one can uphold the idea of using MA as a supplement to ICT or other learning methods. Using appropriate MA can provide new excitement to teachers of dyslexic students in order to get ready in integrating m-learning in teaching session.

A survey done by Ferdig et al. [6] reported that a group of pre-serviced teachers more strongly agreed with the importance of such tools in their own lives. The same group also had a stronger belief that educational apps were accessible to all students, including those with special needs. These statements showed their stronger belief in the ability of apps for customization and differentiation across a wide range of needs. As claimed by Fernández-López et al. [7], mobile application developed with customization and tailored to users with SEN brings many benefits as it helps mould the learning process to different cognitive or sensorial impairments. Consequently, this statement has led to main problem statement to be discussed, which is to dig about acceptance and readiness among teacher who teach dyslexic students in integrating m-learning in teaching.

Conversely, researchers, educators and application developers should take into account a number of considerations when implementing technology for learners, particularly when teaching students with disabilities or special needs. The consideration is important in order to uphold equal education opportunity for all. As in Malaysia, it was a continuous commitment showed by Ministry of Education in providing an excellent education for all Malaysian students that has laid many successes to the foundation for the education system [8]. Acceptance and readiness of implementing technology laid on individual's preference and focus on how they see the future drive of education.

Dyslexia refers to a cluster of symptoms, which result in people having difficulties with specific language skills, particularly reading. People with dyslexia usually experience difficulties with other language skills, such as spelling, writing, and pronouncing words as defined by The International Dyslexia Association [9]. Dyslexia are being suffered by about 10\% - 15\% of the world population as reported in 2010 [9]. Meanwhile, according to Siti Khatijah Nor et al. [10], the number of dyslexic children is raising which is very worrying as up to 2017 , the organization in charged in Malaysia received many enrolment of dyslexic children yearly due to the awareness of Malaysian society on the importance of giving trainings and treatments to remedy the disabilities of the dyslexic children at an early stage.

This paper aims to discover the level of acceptance and readiness of using m-learning among teachers of dyslexic students while addressing the unique learning styles and interests of those students. In parallel to the trend of learning through mobile devices which is a current trend in future learning, it is important to increase the number of appropriate MA to be used for mlearning purpose. Specific objectives are as followed; 
The International Journal of Multimedia \& Its Applications (IJMA) Vol.10, No.6, December 2018

i) How is m-learning acceptance among teachers of dyslexic students?

ii) How is m-learning readiness among teachers of dyslexic students?

The remainder of this paper is organized as follows: related studies about m-learning, and mlearning acceptance and readiness among teachers of dyslexic students, methodology of the study, discussion and conclusion. At the end of this paper, we discuss our findings as teachers' acceptance and readiness identified from the excerpt of the semi-structured interview to clearly answer our research questions. As such, this preliminary study was carried out towards teachers who teaches for five (5) years and above at a dyslexia centre in Klang Valley, Kuala Lumpur.

\section{RELATED STUDIES}

Several terms have to be defined to understand this preliminary study. To support this working paper, appropriate reading had been made towards the important point of it.

\subsection{Mobile Learning}

Mobile learning or m-learning, as a new way to extend education outside a fixed classroom, is gradually gaining on popularity because of the increasing availability of low cost mobile and wireless devices and the supporting infrastructure and technology [11]. M-learning is learning with the assistance of mobile technology. Learning in a mobile environment will become more interesting with the utilisation of mobile tools like smart phones. Besides smart phones, recent innovative technology like tablet PCs or iPad allow integrated applications, which include computing and communication. As young generation of students are well-exposed to the innovative technology, researchers must understand the motivation of using ICT in education.

Main characteristics of m-learning as suggested by Samsiah \& Azidah [12] are learners' mobility, learning virtually anywhere and anytime, via mobile devices. Meanwhile, domain of m-learning includes the new teaching and learning techniques and the wide variety of MA. Dealing with techniques, as well as MA requires teachers to always embrace themselves with up-to-date and relevant information regarding the need of dyslexic children in learning session. Still, acceptance and readiness of implementing technology might influence teachers' motivation for using MA.

Numerous studies have recently focused on dyslexia on different areas. Recent studies by Madeira et.al [13] and Zikl et. al [14] agree that ICT is likely to be a useful tool towards users with dyslexia. For example, a mobile platform based on iPad and iPod touch devices called Picaa designed by Fernández-López et al. [7] with four (4) kinds of educational activities (Exploration, Association, Puzzle and Sorting), aimed to help in the design of learning activities, which can be personalized by teachers at content and user interface levels. Pre-experimental study of Picaa had showed that the use of this learning platform associated with positive effects in the development of learning skills for children who have SEN.

Consequently, Ozdamli \& Cavus [15] claimed that when mobile technologies changed role and responsibility of the learners, the role of the teacher changes slowly towards m-learning. Teachers need to be able to identify the students' interests, relate these interests to topic related learning goals and offer opportunities to reach these goals that are related to the specific conditions a learner is in. It is necessary that the elements of m-learning are organized correctly and the interactions between the various elements are combined in an efficient and optimum way so that the m-learning is successful and the implementation is efficient. Hence, author [15] provide the elements as shown in Figure 1. 
The International Journal of Multimedia \& Its Applications (IJMA) Vol.10, No.6, December 2018

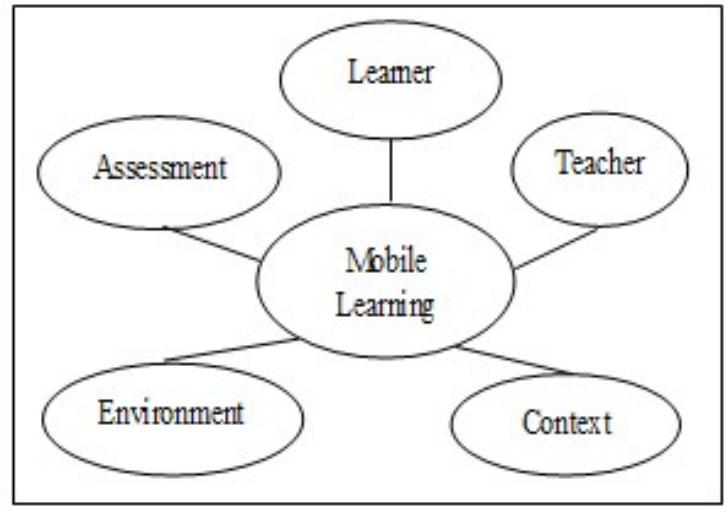

Figure 1. Basic elements of m-learning

Additionally, there were a number of recent ICT applications, also labelled as assistive technology that took place as digital technology that positively impact dyslexic students learning process, as well as instruction supported with mobile technology that associated with increased engagement and improved academic outcomes [16]. Assistive technology are tools that are used by individuals with disabilities to perform functions that might otherwise be difficult or impossible [17]. Essentially, the existence of assistive technology or learning aid for dyslexic students helps them in term of overcoming challenges such as slow note-taking and poor handwriting, thus allowing them to demonstrate their abilities in ways that were once unimaginable [18]. There are variety of assistive technology for dyslexic students as stated by Martin [17], including MA, as shown in Figure 2.

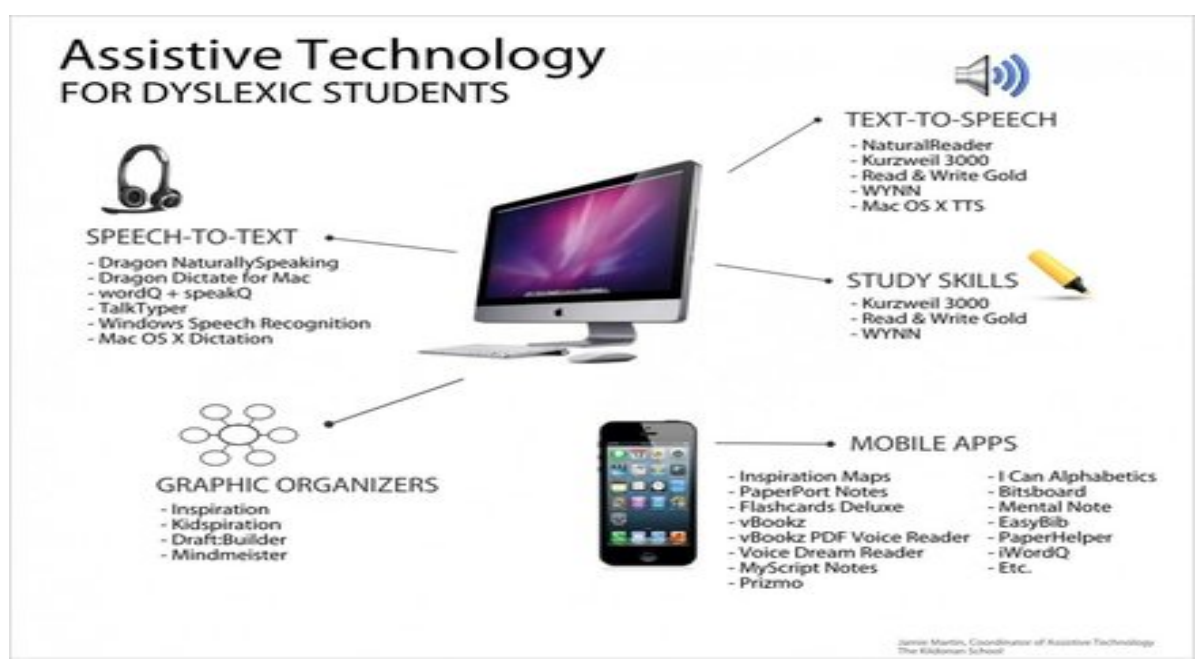

Figure 2. Assistive technology for dyslexic students (Jamie Martin)

A proposed guideline by Madeira et.al [13] suggests some specific recommendations to facilitate ease of reading for dyslexic students, such as:

i) Font style: it is recommended to use MA with font that could maximize the readability of the letters.

ii) Font size: text recommended in 12 to 14 point in size, with no underline or italic form. It should be at least with 1.5 spacing between lines.

iii) Layout: the app should be in form of simple interface with dark coloured text put on a light background. The line should not be too long, maximum with 70 characters only. 
The International Journal of Multimedia \& Its Applications (IJMA) Vol.10, No.6, December 2018

iv) Writing style: should be in short and simple paragraph with clear sentences.

Remarkably, the MA in Android platform known as CinTA, an acronym from Malay phrases "Cara Interaktif Tulis Abjad" had been produced by Azmi et al. [19]. This mobile application give special focus on enhancing the writing skills ability among dyslexic students. The researchers claimed that CinTA had proven that multimedia component that has been applied according to the proper guideline encourage dyslexic students keep more focus and give all the attention to the learning session, as well as performance of student are amazingly increased. CinTA app had been a proof that technologies which are adapted in education really helps the society. Integration of technology in learning will surely take some time, due to several reasons, hence parents and teachers who work with these students need to open their mind and heart to adapt and adopt m-learning in their daily activities. Parents and teachers should also understand the students' learning style and bear with learning obstacle that might occur in the learning process.

Nevertheless, Liaw et al. [20] had drawn the attention to the reality that learning on mobile devices will never fully replace classroom or other electronic learning approaches, but then they believed if leveraged properly, mobile devices can complement and add value to the existing learning styles. Since there have been many suggestions on the most effective ways to educate dyslexic students over the recent years, researchers have start focusing on embracing m-learning for teachers of dyslexic students. Besides, m-learning can boost self-esteem among dyslexic students as it encourage self-learning; learning at own time and pace.

\subsection{Mobile learning acceptance and readiness among teacher of dyslexic students}

M-learning is a new aspect of technology integration for classroom teachers, whereas mobile readiness refers to the extent to which the individuals are willing to use mobile app as a medium that supports learning and teaching process [21]. Teaching student with SEN by using suitable approach and appropriate teaching tools is undeniably a challenging effort to be done if teachers possess lack of preparation or minimal enthusiasm to make it successful. As highlighted by Supyan et al. [22], learning is a process whereby a learner is expected to achieve an intended learning outcome within a given time frame. With teachers as guides or facilitators, in addition to learning resources like books, class notes, learning materials and communication tools, the learning process will become more interesting, meaningful and even productive.

A preliminary study done by Aliff Nawi et al. [2] among Islamic education teachers in Malaysia showed positive acceptance towards using mobile phones as learning tools in teaching and learning. The researchers believed that although this study only choose religious teachers as samples and may differ in other areas of teaching, but it provides an initial overview to the researcher on mobile phone use among religious secondary school teachers. Besides, this study signified the use of m-learning and its impact on teaching and learning. The needs analysis from this study had contributed to findings that were important in assisting the subsequent review of the m-learning module development for the religious teachers.

Meanwhile, Laru [23] focused on the theoretical ideas of scaffolding learning with collaborative scripts and the use of mobile devices as cognitive tools in a real life educational settings. He explored on how to support collaborative learning when students and their activities are supported with mobile technologies. Several number of studies found by Ahmad Fauzi Mohd Ayub et.al [21] showed there were positive attitudes among students towards m-learning, concluded as most students supported the fact that m-learning could increase the flexibility of accessing a variety of resources in learning independently at anytime and anywhere. 
The International Journal of Multimedia \& Its Applications (IJMA) Vol.10, No.6, December 2018

Since dyslexic students need repetitive instructions to enhance their understanding, it seems that multimedia resources can be used to gain mastery in various learning skills. This is for the reason that multimedia resources able to reinforce and motivate students as well as use of multimedia applications can get individuals' attention, improve their understanding and boost their confidence, as stated by Ahmad et. al [24]. This situation has led to real challenge; to empower the teachers with readiness to prepare themselves to teach dyslexic students with appropriate mlearning application.

Technology readiness towards m-learning means the establishment of technology and support to teachers, as well as the need to consider the awareness and adoption of m-learning [21]. The researchers believed the effective use of mobile technologies such as internet browsing and uploading/downloading relied much on the acceptance of the users (teachers and students) to use them in the teaching and learning process. Findings from this study had led to the gap of this study; acceptance and readiness of m-learning among teachers of dyslexic students. The progress fostered the issue that teachers are to be ready with pedagogical techniques which offer innovative approach of using the mobile technology in their teaching. Mobile technology can also provide new sets of work culture that may shape the way user communicate and manage time effectively in m-learning environment.

Innovation in mobile app has raised interest to apply m-learning concept among teachers because it facilitates teaching and learning, as claimed by Johnson et al. [25]. Then, they have to get ready to utilize the technology associated with m-learning in the teaching and learning process towards dyslexic students. In the case of students with SEN, learning exercises must be individualized in order to meet their SEN as well as help them to learn [7]. Teachers at the same time should prepare relevant exercises to be carried out, personalize the exercises, supervise and guide those students. Statistic by GSMA [26] has predicted that the number of mobile subscribers is to reach 5.9 billion by 2025 , equivalent to $71 \%$ of the world's population, and this shows that mobile technology has gradually grown all around the world.

\section{MATERIAL AND Method}

\subsection{Participant of Study}

The participants of this preliminary study consisted of four (4) teachers who have been teaching mild level of dyslexic students for five (5) years and above at a dyslexia centre in Klang Valley, Kuala Lumpur. Throughout the years, they entertained a number of students from the age of 7 years old to 13 years old in the class, which have the similarity of mild level of dyslexia. Teachers who teach intermediate and severe level of dyslexia were not involved in this scope of study.

The interview questions were obtained and adapted from several studies, namely studies in revealing mobile acceptance and readiness among teachers, regardless of who their students are. There were few questions asked, such as type of mobile technology that teachers possessed, type of use of mobile phone/devices application, what kind of learning activities that teachers conduct by utilizing the mobile phone/devices and the main question for this study; acceptance and readiness of using m-learning in classroom setting.

\subsection{Research Setting}

Data collection for this preliminary study took place at a dyslexic centre under non-government organization in Kuala Lumpur. The teachers available for participation were purposely selected after having their willingness to join the preliminary study. Since there were only four (4) of them who teach mild level of dyslexic students, the researchers selected all four teachers to be interviewed. Research described in this study was conducted as a part from evaluation of MA that 
The International Journal of Multimedia \& Its Applications (IJMA) Vol.10, No.6, December 2018 were used among dyslexia students in learning English language. In order to understand the students' learning needs and styles, their respected teachers were likely to be involved in the study as well.

The study was carried out by means of an interview which comprise of three (3) groups of a few open type questions. The first group of questions provided demographic data about teachers' gender, age, working experience and identified possessing of a mobile device. The second group of questions investigate m-learning acceptance in general, while the third group of questions collected information about m-learning readiness.

\subsection{Research Method}

The study was done qualitatively. Semi-structured questions were used as questions were given as the items, as the participants were given question as guideline. The rest, they tried hard to answer the question freely based on their opinion. The study was conducted in three (3) phases, briefly discussed as follows:

i) Planning: the objectives were formulated. Appointment was set up with selected teachers. Researchers had shown selected MA to be used for evaluation purpose by the teachers.

ii) Interview: semi-structured questions had been developed to be used in interview sessions.

iii) Analysis of findings and discussion: interview with selected teachers had been considered as single case study. The teachers had provided report concerning their acceptance and readiness towards m-learning.

During planning phase, teachers were required to go through a number of MA in learning English that had been selected for evaluation. Those MA were selected based on keyword, then shortlisted for evaluation purpose. Finally, there was one (1) MA chosen based on dyslexic' learning need as proposed by Madeira et. al [13].

The teachers were given two (2) weeks' time to explore the features of each MA. As their first time with the MA, they easily understood the functionalities. Following that, a semi-structured interview had been set up to reveal their feelings and experience towards using the particular MA. The interview had led to the researchers' understanding of teachers' experience. From the findings, researchers had analysed and reported the results in the Discussion part.

\section{RESULT AND DISCUSSION}

\subsection{Demographic of Participant}

In this preliminary study, researchers managed to meet four (4) teachers in two (2) different interview sessions. Averagely, the interview session took time about thirty minutes for each participants. Some data of the participants were presented in Table 1.

Table 1: Interview participants

\begin{tabular}{|c|c|c|c|c|}
\hline Teacher Name & Gender & Age & $\begin{array}{c}\text { Years of working at } \\
\text { this centre }\end{array}$ & $\begin{array}{c}\text { Possess Mobile } \\
\text { Devices? }\end{array}$ \\
\hline A (Ina) & Female & 45 & 12 & Yes \\
\hline B (Mar) & Female & 33 & 5 & Yes \\
\hline C (Wan) & Male & 37 & 7 & Yes \\
\hline D (Lia) & Female & 48 & 10 & Yes \\
\hline
\end{tabular}


The International Journal of Multimedia \& Its Applications (IJMA) Vol.10, No.6, December 2018

Above all, the similarity of these participants was the possession of their own mobile devices. This criteria had made the interview session ran smoothly as they had clear understanding about the reason they were selected for this preliminary study. Possession of own mobile devices somehow can give influence, either positive or negative to the teachers, as they can opt whether to integrate m-learning or not. Besides, there were only four (4) of them who took charge of mild level dyslexic students at that centre. Undeniably, their perception and opinion were so important to this study.

\subsection{Mobile Learning Acceptance}

Prior to the interview, participants were granted with ample time to evaluate the selected MA. During the interview, they confidently managed to deliver their idea regarding the questions given. To the question "Do you accept the use of mobile application in classroom?", all the participants showed their acceptance of using MA in classroom setting to assist learning of dyslexic students. They believed that appropriate MA can boost the intention to learn among the students by creating an incredible support system to the students themselves.

This idea was aligned with suggestion by Hennigh [27] who believed that teachers can adopt some strategies to support dyslexic students, such as adapt and evaluate the activities, adjust the instruction to the child using alternative methods of instruction, self-learning and autonomy or use diverse texts, with rhythm and repetition. Thus, MA that use text, image and animation with concept of repetition can be considered as an appropriate learning tool for dyslexic students.

However, all the teachers admitted that current implementation at the centre did not portray the thorough use of MA in classroom setting. Limited facilities in the centre did not encourage the use of MA during teaching and learning sessions. It all then dependable on teachers' readiness to adopt mobile devices and use suitable MA in class. In reality, the growing number of mobile users automatically influences the growth of MA that are available in the download platforms, such as the App Store and the Play Store [28].

Early intervention is the most effective way of helping dyslexic students [13], hence MA used should certainly focus on reading skill, as it is essential for success in school, work and society. By contrast, most of the MA available in the digital stores did not consider this as a priority, yet they were tend to focus only on commercial value, like colourful and lengthy in explanation. As a matter of fact, MA with relevant learning theory is to be used for the sake of dyslexic students learning.

Consequently, teachers of dyslexic students firstly should accept the concept of m-learning to be applied in the students' learning, so that the teachers really know which MA to be used for learning purpose. Riska Ayu et al. [29] believed that understanding students' perspectives can assist teachers in integrating the technology in classroom, so can increase and improve the quality of the learning process.

\subsection{Mobile Learning Readiness}

There were a few questions asked in this section, mainly about teachers' readiness to use mobile learning during teaching and learning sessions. One of the relevant question in this section was "Are you ready to fully use mobile application as learning tool for dyslexic students in your teaching session?". Regarding this, there were really stimulating findings to share. Teacher A and $\mathrm{B}$ had agreed they were ready to use MA as learning tool for dyslexic students in classroom setting, as long as simple recommendations that suit materials for dyslexic students are to be 
The International Journal of Multimedia \& Its Applications (IJMA) Vol.10, No.6, December 2018

fulfilled. From their personal opinions, Teacher A said MA for dyslexic students should be in simple text, and this is in line with their ability to read and understand text can be affected by the way in which text has been written and produced by [13].

Meanwhile, Teacher B was very eager to utilize the MA as learning tool, as long as there are sufficient mobile devices, installed with appropriate MA for each student in her class during the teaching and learning sessions. Current practice of teaching session at the centre was using whiteboard and marker, and only once in a while the dyslexic students were brought to the only computer lab that they have with restricted number of desktops and Internet connection to date.

Interestingly, Teacher $\mathrm{C}$ had expressed his view in readiness of using MA for dyslexic students, which he will be ready to fully engage the students in class with mobile devices, providing parents of dyslexic students were also to be ready to use it. He believed in an approach that cooperation from the parents will support the learning process outside classroom setting. This approach helps students to be able to do it and conduct each activity by themselves.

As pointed out by Waiyakoon et al. [30], scaffolding approach is the method of learning support by using proper conceptual scaffolding of learners into learning object on tablet. Dyslexic students can make the lesson revision at home, with the help from their parents when they are around. Teacher $\mathrm{C}$ had emphasized that people around dyslexic students, most probably the parents and teachers should provide more attention to dyslexic students learning, so that dyslexic students can increase their performance and confidence level in learning. This aligned with Jamilah et al. [31], which revealed that dyslexic students potentials must be identified from the outset of their learning to help tailor proper teaching methods by their teachers and to help the students choose proper courses that are aligned with their potentials.

On the other hand, Teacher $\mathrm{D}$ as the eldest participants showed a little bit hesitation in readiness to apply m-learning for dyslexic students for a few reasons. She realized that handling mobile devices, especially with dyslexic students was not an easy job. Those students possibly would feel interested when first time introduced to the devices. This situation might likely lead to either making learning go smooth or slower it down. In addition, Teacher D was also concerned about using inappropriate MA in the classroom, as she acknowledged her shortage of knowledge in selecting the appropriate ones. As a mathematics teacher, she preferred using conventional approach in teaching dyslexic students, using building blocks and magic colour in class. Though, she has given the words that she will join related courses or workshops to enhance her knowledge in related subject, if she was asked to by her employer.

These findings showed that m-learning acceptance and readiness among teachers of dyslexic students were influenced by several number of factors, likely MA features should suit dyslexic students learning needs, sufficient facilities in class such as mobile devices, Internet connection and additional learning materials during learning session with dyslexic students, engagement from people around dyslexic students especially their parents and selection of definite suitable MA to be used in class. This is in line with finding by Domingo \& Gargante [32] that understanding teachers' perceptions of mobile technology provides a means for promoting a more meaningful use of this technology in the classroom setting. Definitely there are many more factors to be listed, however the factors are not discussed in this study.

\section{FUTURE WORK AND CONCLUSION}

This study is directed to deepen our knowledge about m-learning acceptance and readiness among selected teachers of dyslexic students at mild level in a dyslexia centre in Klang Valley. Findings provide significant information on the impact of m-learning that teachers perceive, the frequency 
The International Journal of Multimedia \& Its Applications (IJMA) Vol.10, No.6, December 2018

of use of relevant MA in the classroom, and the differences in the perception of the impact on learning of mobile technology among users/non-users of MA [32]. Nevertheless, user are still likely to study the advantages and disadvantages of using m-learning in their own preferences, as they have their own purpose and precedence.

The responses for two (2) areas of preliminary study namely the acceptance and readiness were interpreted. On the whole, participants welcomed the idea of integrating $\mathrm{m}$-learning into related subject for dyslexic students. However, they believed that integrating m-learning for dyslexic students need major change of attitude and moral support towards dyslexic students themselves. The real challenge is to create an engaging m-learning environment inside and outside classroom setting. There is also a challenge in how to boost teachers' acceptance to assist dyslexic students in using mobile technology. Thus, every stakeholder in this field should suggest suitable approaches to be implemented in order to uphold the objective.

Although, at this stage our preliminary study has limitations in that the sample of teachers interviewed is in small number and only covers one dyslexic centre as it was a qualitative study. Even though, the preliminary results show a positive attitude from the teachers of dyslexic students in terms of m-learning acceptance and readiness. Some researchers believed that teachers should first accept and ready to adapt and adopt the m-learning, then they will able to increase attention and motivation among dyslexic students [33]. Yet, there are not many MA which cater the importance of handwriting technique, as well as research on mathematical disabilities is very limited [34].

Our ongoing work aims to evaluate usability of selected MA for learning among dyslexic learners. For future work, more research with a larger sample from similar institutions of dyslexia centre will provide a better and clearer insight into the issue of acceptance and readiness of integrating m-learning. Besides, the parents of selected dyslexic students should be part of the study to complement findings of the study. Determining the best strategies for successfully implementing mobile devices to improve learning is an important issue that need intense study especially in integrating m-learning into classroom environments. M-learning is proving its potential to address authentic learner needs at the point at which they arise [35].

\section{ACKNOWLEDGEMENTS}

The authors would like to thank MIRGS-IIUM for financial support for the research and Research Management and Innovation Centre, UPSI, Malaysia for covering the publication cost of this article.

\section{REFERENCES}

[1] Benmarrakchi, F., El Kafi, J., Elhore A. \& Haie, S. (2016). Exploring the use of the ICT in supporting dyslexic students' preferred learning styles : a preliminary evaluation. Education Inf Technology. pp.

[2] Aliff Nawi, Mohd Isa Hamzah \& Azwin Arif Abdul Rahim (2015). Teachers acceptance of mobile learning for teaching and learning in Islamic education: a preliminary study. Turkish Online Journal of Distance Education (TOJDE), ISSN 1302-6488, Vol 16, No. 1, Article 12, pp.

[3] Koifman, J. (2017). Teaching students with specific education needs. International Journal of Innovation and Research in Educational Sciences, Vol. 4, No. 3, ISSN (Online), pp. 2349-5219.

[4] Ok, M. W., Kim, M. K., Kang, E. Y., \& Bryant, B. R. (2015). How to find good apps: an evaluation rubric for instructional apps for teaching students with learning disabilities. Intervention in School and Clinic, Vol. 51, No. 4, pp. 244-252.

[5] The Regents of the University of Michigan (2018). Retrieved from http://dyslexiahelp.umich.edu/tools/apps 
The International Journal of Multimedia \& Its Applications (IJMA) Vol.10, No.6, December 2018

[6] Ferdig, R. E., Pytash, K. E., Kosko, K. W., Gandolfi, E., \& Mathews, R. (2016). Use and perceptions of mobile applications and technologies by those interested in special education. Kent, OH: Kent State University. Retrieved from http://spedapps.kent.edu/2016survey.pdf.

[7] Fernández-López, A., Rodríguez-Fórtiz, M. J., Rodríguez-Almendros, M. L. \& Martínez-Segura, M. J. (2013). Mobile learning technology based on iOS devices to support students with special education needs. Computers \& Education, Vol. 61, pp. 77-90.

[8] Malaysia Education Blueprint 2013-2025 Preliminary Report (2012). Ministry of Education.

[9] The International Dyslexia Association (2013). Dyslexia in the classroom: what every teachers needs to know. IDA: Baltimore.

[10] Siti Khatijah Nor A. R, Nur Hasni N., Anis Zafirah A., Rosida A.J., Zainab M. \& Ini Imaina A. (2018). Designing mobile application for dyslexia in reading disorder problem. International Journal of Academic Research in Business and Social Sciences, Vol. 8, No. 1, pp. 628-646.

[11] Jalil, A., Beer, M. \& Crowther, P. (2015). Pedagogical requirements for mobile learning: a review on MOBIlearn task model. Journal of Interactive Media in Education, Vol. 1, No. 12, pp. 1-17.

[12] Samsiah Bidin \& Azidah Abu Ziden. (2013). Adoption and application of mobile learning in the education industry. Procedia - Social and Behavioral Sciences, Vol. 90, pp. 720 - 729.

[13] Madeira, J., Silva, C., Marcelino, L. \& Ferreira, P. (2015). Assistive mobile applications for dyslexia. Procedia Computer Science, Vol. 64, pp. 417 - 424.

[14] Zikl, P., Bartošová, I. K., Víšková, K. J., Havlíčková, K., Kučírková, A., Navrátilová, J., \& Zetková, B. (2015). The possibilities of ICT use for compensation of difficulties with reading in pupils with dyslexia. Procedia - Social and Behavioral Sciences, Vol. 176, pp. 915-922.

[15] Ozdamli, F. \& Cavus, N. (2011). Basic elements and characteristics of mobile learning. Procedia Social and Behavioral Sciences, Vol 28, pp. 937 - 942.

[16] Elazab Elshazly \& Elazab Mohamed (2016). A case study of an intervention program for students with dyslexia in a primary school in the UAE. Electronic Theses and Dissertation: United Arab Emirates University.

[17] Martin, J. (2015). Assistive Tech 101: Basic for Students with Dyslexia. Retrieved January 14th, 2017 from https://assistedtechnology.weebly.com/dyslexia-and-at-connor-mahoney.html

[18] The Yale Center for Dyslexia and Creativity (2017). Tools and technology. Retrieved June 22nd, 2018 from http://dyslexia.yale.edu/resources/tools-technology/

[19] Azmi, A. Z, Nasrudin, N. H., Wan Azman W. N. \& Ahmad Junid, R. (2017). Mobile application to enhance writing skills ability among dyslexic children: CiNTA. Journal of Fundamental and Applied Science, Vol. 9, No. 5S, pp. 195-209.

[20] Liaw, S., Hatala, M. \& Huang, H. (2010). Investigating acceptance toward mobile learning to assist individual knowledge management: based on activity theory approach. Computers \& Education, Vol. 54, pp. 446-454.

[21] Ahmad Fauzi Mohd Ayub, Syaza Hazwani Zaini, Wong Su Luan \& Wan Marzuki Wan Jaafar (2017). The influence of mobile self-efficacy, personal innovativeness and readiness towards students' attitudes towards the use of mobile apps in learning and teaching. International Journal of Academic Research in Business and Social Sciences, Vol. 7, pp. 364-374.

[22] Supyan Husin, Mohd Radzi Manap, Zaini Amir \& Pramela Krish (2012). Mobile learning readiness among Malaysian students at higher learning institutes. Asian Social Science, Vol. 8, No. 12, pp. 276283.

[23] Laru, J. (2012). Scaffolding learning activities with collaborative scripts and mobile devices (Academic dissertation). University of Oulu, Finland.

[24] Ahmad, S. Z., Jinon, N. I., \& Rosmani, A. F. (2013). MathLexic: An assistive multimedia mathematical learning aid for dyslexia children. Paper presented at IEEE Business Engineering and Industrial Applications Colloquium (BEIAC), pp. 390-394.

[25] Johnson, L., Adams, S., \& Cummins, M. (2012). Mobile apps. The NMC Horizon Report: 2012 Higher Education Edition. Austin, Texas: The New Media Consortium.

[26] GSMA (2018). The Mobile Economy 2018. Report. GSM Association.

[27] Hennigh, K. A. (1995). Understanding Dyslexia: A Professional's Guide. USA: Teacher Created Resources.

[28] Moumane, K., Idri, A. \& Abran, A. (2016). Usability evaluation of mobile applications using ISO 9241 and ISO 25062 standards. Springer Plus, Vol. 5, No. 548, pp. 1-15.

[29] Riska Ayu, A., Rhomiy, A., Nilza Humaira, S. \& Wahyu, S. (2017). The Perceptions of students and teachers about the use of edutainment instructional media in mathematics learning. Advances in Social Science, Education and Humanities Research (ASSEHR), Vol. 160, pp. 228-234. 
The International Journal of Multimedia \& Its Applications (IJMA) Vol.10, No.6, December 2018

[30] Waiyakoon, S., Khlaisang, J. and Koraneekij, P. (2015). Development of an instructional learning object design model for tablets using game-based learning with scaffolding to enhance mathematical concepts for mathematic learning disability students. Procedia - Social and Behavioral Sciences 174, pp. $1489-1496$.

[31] Jamilah Hamid, Nor Hasbiah Ubaidullah, Khairul Anuar Samsudin, Aslina Saad \& Saira Banu Omar Khan (2014). Requirement analysis for the development of a directed exploration virtual reality potentials diagnosis system for dyslexic children. Australian Journal of Basic and Applied Science, Vol. 8, No. 23 Special, pp. 44-52.

[32] Domingo, M. G \& Gargante, A. B. (2016). Exploring the use of educational technology in primary education: Teachers' perception of mobile technology learning impacts and applications' use in the classroom. Computers in Human Behavior 56, pp. 21-28.

[33] Roldán-Álvarez, D., Martin, E. , García-Herranz, M. \& Haya, P. A. (2016). Mind the gap: impact on learnability of user interface design of authoring tools for teachers. International Journal of HumanComputer Studies, Vol. 94, pp. 18-34.

[34] Tariq, R. \& Latif, S. (2016). A mobile application to improve learning performance of dyslexic children. Educational Technology \& Society, Vol. 19, No. 4, pp. 151-166.

[35] Kukulska-Hulme, A. (2018). Mobile-assisted language learning. Retrieved June 8th, 2018 from http://oro.open.ac.uk/57023/1/_userdata_documents5_ak35_Desktop_Accepted\%20Manuscript_Con cise $\% 20$ Encyclopedia.pdf

\section{AUTHORS}

Nor Zuhaidah Mohamed Zain is a lecturer at Faculty of Art, Computing and Creative Industry at Universiti Pendidikan Sultan Idris. She received Bachelor Degree in Information Technology from Universiti Utara Malaysia in 2001 and Master of Science (Information Technology) from Universiti Teknologi MARA in 2005. Her research interests lie in the area of multimedia learning in education and implementation of mobile learning, focusing on special education needs.

Murni Mahmud (Ph.D) is an associate professor at Kuliyyah of Information Technology, IIUM in the field of Human Computer Interaction (HCI). Her research interest is in the area of user experience design, interaction design evaluation methods, usability and accessibility of user interfaces on websites and mobile applications. Before joining IIUM, she was a Project Systems Analyst at Esso Malaysia Berhad (currently known as Exxon-Mobil).
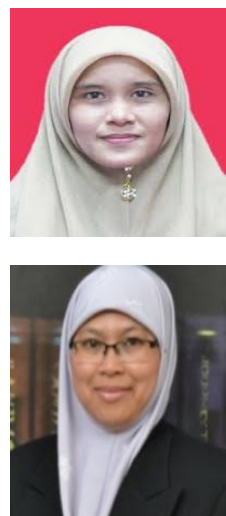